\title{
The environmental investments justification
}

\author{
Anna Gurko ${ }^{1, *}$, Svetlana Oparina $^{2}$, Lidia Vasyutkina ${ }^{3}$ and Elena Potekhina $^{4}$ \\ ${ }^{1}$ Moscow State University of Civil Engineering, 26 Yaroslavskoye Shosse, Moscow, 109377, Russia \\ ${ }^{2}$ Moscow Metropolitan Governance University, 28 Sretenka, Moscow, 107045, Russia \\ ${ }^{3}$ Bauman Moscow State Technical University, 5, str. 1, 2-ya Baumanskaya, Moscow, 105005, Russia \\ ${ }^{4}$ Russian State Social University, 4, str. 1, Vilgelm Pik street, Moscow, 129226, Russia
}

\begin{abstract}
The article reveals the problems of improving environmental impact assessment and justification of the economic investments of industrial enterprises. The existing tools for environmental impact assessment are analyzed, information on the role and place of environmental impact assessment and investment design in the justification of the planned economic activity is systematized. For this purpose, considerable attention is paid to the analysis and synthesis of existing methodological approaches to this problem. The authors propose to consider environmental impact assessment and justification of environmental investments as a process aimed at making environmentally oriented management decisions on the feasibility and economic feasibility of implementing planned economic activities, the reasonableness of capital investments, taking into account possible adverse environmental, social, economic impacts and developing measures for their reduction and prevention. Based on the study, the authors developed a classification of the causes of environmental pollution, presented in the form of a tree of systems, allowing for a clear decomposition of the causes of pollution of the environment, specifying and refining the targeting of environmental measures necessary to reduce pollution. This research direction is also complemented by the development of a strategy (decision tree) and a mathematical description of the simulation procedure, which allows real-time making an objectively reasonable choice of options for implementing the planned economic activity, taking into account the totality of known information.
\end{abstract}

\section{Introduction}

According to the Russian environmental legislation, any economic activity carried out on the territory of the Russian Federation must comply with the requirements of the organization of environmental management and prevent the occurrence of adverse environmental impacts [Law of the Russian Federation "On Environmental Protection" dated 10.01.2002 No. 7-FZ]. The essence of investment, as a form of capital investment and the development of economic activity, is not only to make a profit, but also to solve environmental problems: the decision to implement the proposed investment project should be accompanied by an assessment of its environmental and economic consequences.

\footnotetext{
*Corresponding author: ai_gurko@mail.ru
} 
The existing toolkit for environmental impact assessment is more focused on the statement of negative impact factors and, to a lesser extent, on the preventive assessment of the environmental and economic consequences of the planned economic activity. The practice of environmental impact assessment is often limited to the forecast of such characteristics of the planned economic activity as the amount of resources used; emissions and discharges, waste generated, etc.

In accordance with the current regulatory methodological framework, the process of preparing an investment project involves the sequential implementation of three main stages: the formation of an investment plan, the preparation of a rationale for investment, the preparation of a feasibility study and / or a working draft.

At all these stages, the process of assessing the impact on the environment and evaluating the effectiveness of investment processes passes separately from each other. Economic and environmental aspects in investment activities are in most cases considered separately, often without regard to their interrelationship and interdependence. All these facts do not allow to fully use the accumulated scientific and practical potential when making environmental and economic decisions about the possibility and conditions for the implementation of the planned economic activity. In this regard, the improvement of the EIA toolkit and the justification of environmental investments of industrial enterprises is an urgent and practically important problem.

Therefore, the purpose of this study is to develop a mathematical model for the adoption of environmental and economic management decisions on the possibility and conditions for the implementation of the planned economic and production activities of the organization.

The following abbreviations are used in the work:

EIA - environmental impact assessment;

IP - investment project;

AEE - absolute economic efficiency;

DC - discounted costs;

NPV - net present value;

Pm -payments;

API - atmospheric pollution index;

PED - prevented environmental damage from pollution;

TS - tree of systems;

$\mathrm{TG}-$ tree of goals.

\section{Materials and Methods}

Analyzing the stages of the development of EIA abroad and the accumulated practical experience of preparing and making decisions taking into account environmental and economic factors, it can be noted that the legislative consolidation of EIA procedures in foreign practice marked in the 70s a transition to a "preventive" approach, in which before making a decision on the implementation of a project, environmental changes are simulated that can follow its implementation.

The purpose of the EIA is to prepare management decisions taking into account environmental and economic factors when making economic and other decisions [Russian Standard «The regulation on the assessment of the impact of the planned economic and other activities on the environment in the Russian Federation». Approved by order of the State Committee on Ecology of Russia dated 05.16.2000 No. 372.].

The practice and experience of the world community in the field of solving environmental and economic problems helped Russia to start developing and mastering the EIA methodology and begin to apply it in preparing business decisions. Of fundamental importance in the organization of this activity was the creation of a state environmental 
review, analysis and synthesis of the results of which allowed us to formulate goals and objectives for carrying out an EIA, identify the executors and participants of this process, determine the role of the public and establish the responsibility of the customer for breaking the rules in this area.

The most significant environmental and economic indicators of EIA include damage and payments for a negative impact on the environment. The latter are an economic lever for the accumulation and redistribution of funds in order to use them most effectively in the implementation of environmental protection measures, and also serve as an economic incentive for the implementation of an active environmental policy in the Russian Federation.

In addition, there are economic performance indicators used in the evaluation of IP. They are determined in accordance with the Guidelines for evaluating the effectiveness of IP and their selection for funding [Russian Standard «Guidelines for evaluating the effectiveness of investment projects (Second edition) (NPO Ed. Economy, Moscow, 2000]. Evaluation of the effectiveness of IP implies the existence of a significant information base, most of which does not have the necessary completeness and accuracy, which affects the reliability of estimates of the feasibility and effectiveness of the project.

Taking this into account, to predict the consequences of possible environmental changes, it is necessary to combine the procedures for carrying out an EIA and an IP to determine the possible environmental, social and economic consequences of a project, as well as to estimate investment costs for ensuring environmental safety in the zone of influence of an object.

Taking into account the need to process large arrays of diverse information, the model used methods that, depending on the nature of the data, use information and mathematical modeling technologies as a means of such processing. The latter allows to ensure the objectivity and complexity of the process of justifying the adopted environmental and economic decisions.

The most frequently used methods for predicting the impact include simulation modeling, the method of expert estimates, the method of analogies [1].

To make ecological and economic decisions, it is necessary to create a model that includes the projected object and its environment as elements (subsystems). Such a dynamic model should be suitable for conducting simulation. Its use allows you to compare various options for design decisions on environmental impacts.

When building such a model, it is advisable to divide the entire set of causes of environmental pollution into two groups: organizational-economic and subjective (human factor) and presented as a system tree. TS clearly shows an orderly hierarchy of causes of pollution of the environment, expresses their coordination and internal relationships. In contrast to the usual classification, TS allows for a clearer decomposition of the causes of pollution of environment, suggesting their specification and clarification of targeting. 


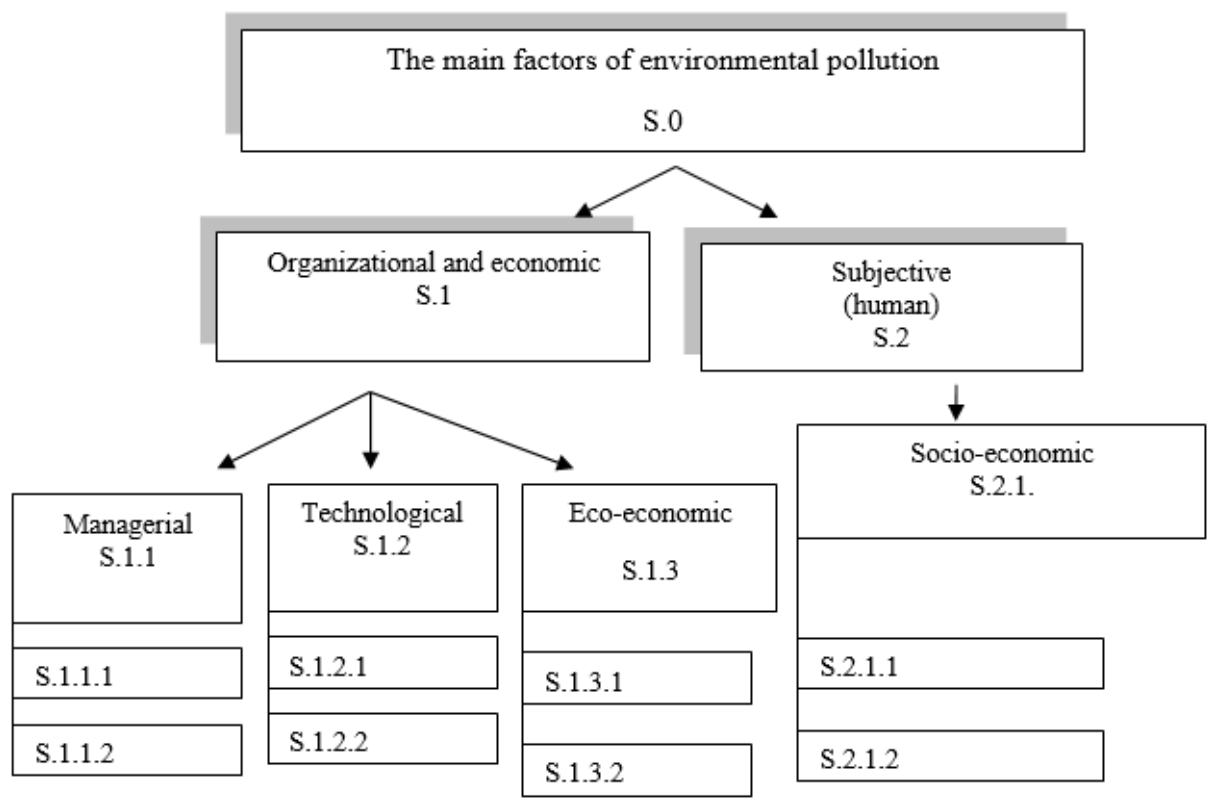

Fig. 1. Tree of pollution systems, where:

S.1.1.1 - Lack of knowledge of the legal framework for environmental protection;

S.1.1.2 - Inadequate organizational and technical support;

S.1.2.1 - Violation of waste disposal technologies;

S.1.3.1 - Excessive emissions, discharges;

S.1.3.2 - Insufficient financing of environmental protection measures.

S.2.1.1 - Demographic position (characteristic);

S.2.1.2 - Estimated change in social conditions of life of the population.

The next step was to build a tree of goals, which is designed to determine the concretization of the main goal. The concretization of the main goal within the framework of decision-making is designed to solve the following main tasks: how to match the objective functions with the resources that need to be redistributed among several private goals; and how to minimize the chance of serious mistakes when making decisions.

We will build a tree of goals in relation to the process of making ecological and economic decisions on the possibility and conditions for the implementation of production activities.

The objectives of the first level are the group of economic and environmental private goals. The objectives of the second level are the quantitative parameters characterizing private goals: absolute economic efficiency (AEE); discounted costs (DC); net present value (NPV); payments (Pm); atmospheric pollution index (API), prevented environmental damage from pollution (PED). The latter is a monetary assessment of the possible negative effects of environmental pollution, which were avoided as a result of environmental activities, environmental measures and programs aimed at maintaining or improving the qualitative and quantitative parameters that determine the environmental quality (condition) of the environment as a whole and its separate ecological-resource components. 


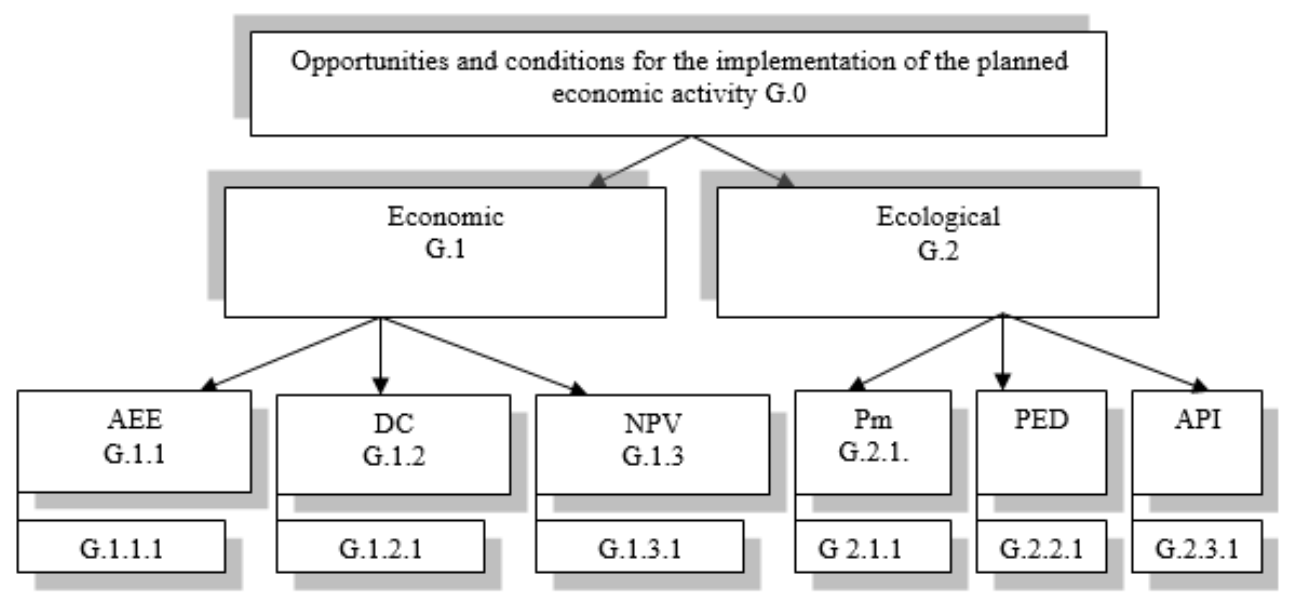

Fig. 2. Tree of goals for making ecological and economic decisions about the possibilities and conditions for the implementation of the planned economic activity.

The decomposition of goals into private ones allows them to more specifically analyze them and reduce the likelihood of serious mistakes inherent in making complex decisions.

The formation of a representative set of options for environmental and economic decisions about the possibilities and conditions for the implementation of the planned production activity occurs when the system tree and the goal tree interact. TS allows you to define a list of measures to eliminate each of the characteristic causes of pollution of the environment, and TG - how each specific action from the formed subsets can affect the change of each target indicator.

The justification of the optimization procedure is reduced to the choice of the decisionmaking method in the conditions of uncertainty and conflict. One of the most effective decision-making methodologies under these conditions is provided by game theory and, in particular, the "game with nature" [2]. In such tasks, the choice of solution depends on the state of objective reality, called "nature", and the mathematical models are called "games with nature."

Traditionally, the "game with nature" solution of the task is reduced to the construction of a "payment matrix" containing "costs" (values of selection criteria) of each option for each of the states of "nature" (selection criteria characterizing a particular goal).

At the first stage, it is necessary to form an intermediate "payment matrix", which contains the absolute values of particular goals (selection criteria). We form an intermediate payment matrix containing the absolute values of particular goals (selection criteria).

Table 1. Intermediate "payment matrix" of "game with nature".

\begin{tabular}{|c|c|c|c|c|c|c|c|c|}
\hline \multirow{3}{*}{$\begin{array}{c}\text { Option of } \\
\text { environmental } \\
\text { and economic } \\
\text { decisions }\end{array}$} & \multicolumn{8}{|c|}{ "Condition of nature" } \\
\hline & \multicolumn{8}{|c|}{ Particular goals $\left(f_{\mathrm{k}}\right)$} \\
\hline & $\begin{array}{c}\text { AEE } \\
\left(P_{1}\right)\end{array}$ & $\begin{array}{l}\text { DC } \\
\left(\mathbf{P}_{2}\right)\end{array}$ & $\begin{array}{l}\text { NPV } \\
\left(\mathbf{P}_{3}\right)\end{array}$ & $\begin{array}{l}\mathbf{P m} \\
\left(\mathbf{P}_{4}\right)\end{array}$ & $\begin{array}{r}\text { PED } \\
\left(\mathbf{P}_{5}\right)\end{array}$ & $\begin{array}{l}\text { API } \\
\left(\mathbf{P}_{6}\right)\end{array}$ & $\cdots$ & $\begin{array}{c}\cdots \\
\left(\mathbf{P}_{m}\right)\end{array}$ \\
\hline $\mathrm{O} 1$ & $\mathrm{AEE}_{11}$ & $\mathrm{DC}_{12}$ & $\mathrm{NPV}_{13}$ & $\mathrm{Pm}_{14}$ & $\mathrm{PED}_{15}$ & $\mathrm{API}_{16}$ & $\ldots$ & $\mathrm{a}_{1 \mathrm{~m}}$ \\
\hline $\mathrm{O} 2$ & $\mathrm{AEE}_{21}$ & $\mathrm{DC}_{22}$ & $\mathrm{NPV}_{23}$ & $\mathrm{Pm}_{24}$ & $\mathrm{PED}_{25}$ & $\mathrm{API}_{26}$ & $\ldots$ & $\mathrm{a}_{2 \mathrm{~m}}$ \\
\hline
\end{tabular}




\begin{tabular}{|l|l|l|l|l|l|l|l|l|}
\hline O3 & $\mathrm{AEE}_{31}$ & $\mathrm{DC}_{32}$ & $\mathrm{NPV}_{33}$ & $\mathrm{Pm}_{34}$ & $\mathrm{PED}_{35}$ & $\mathrm{API}_{36}$ & $\cdots$ & a3m \\
\hline$\cdots$ & & & & & & & & \\
\hline $\mathrm{O}_{\mathrm{n}}$ & $\mathrm{AEE}_{\mathrm{n} 1}$ & $\mathrm{DC}_{\mathrm{n} 2}$ & $\mathrm{NPV}_{\mathrm{n} 3}$ & $\mathrm{Pm}_{\mathrm{n} 4}$ & $\mathrm{PED}_{\mathrm{n} 5}$ & $\mathrm{API}_{\mathrm{n} 6}$ & $\cdots$ & $\mathrm{a}_{\mathrm{nm}}$ \\
\end{tabular}

In the intermediate "payment matrix", the options considered are pre-determined combinations of environmental and economic decisions about the possibility and conditions for the implementation of the planned activity. The "conditions of nature" (particular goals $\mathrm{f}_{\mathrm{k}}$ ) are the parameters of AEE, DC, NPV, Pm, PED, API and others, which in general can have different dimensions, and the "cost" of solutions $\mathrm{a}_{\mathrm{nm}}$ - numerical values of the particular goal $\mathrm{m}$ of the solution options $\mathrm{n}$.

To solve the "payment matrix" by the absolute values of particular goals $\left\|a_{n m}\right\|$, it is necessary to perform a number of auxiliary operations, the essence of which boils down to a gradual adequate replacement in the matrix of solutions of the absolute values of the parameters by their estimated values. Normalized estimated values eliminate the problem of differences in dimensions, are more convenient and unequivocally interpret the value ("cost") of the variant for each of the particular goals. As a result, the decision matrix $\left\|a_{n m}\right\|$, by absolute values of particular goals is transferred to the decision matrix $\left\|c_{n m}\right\|$ by the degrees of their realization, which is the final "payment matrix" of the "game with nature" (Table 2), in which each variant of solutions On implemented in the "conditions of nature" Pm there corresponds a certain amount of "value", i.e. the consequences of making this decision $\mathrm{Cnm}$.

Table 2. The final "payment matrix" of "game with nature".

\begin{tabular}{|c|c|c|c|c|c|c|c|c|}
\hline \multirow{3}{*}{$\begin{array}{c}\text { Option of } \\
\text { environmental } \\
\text { and economic } \\
\text { decisions }\end{array}$} & \multicolumn{8}{|c|}{ "Condition of nature" } \\
\hline & \multicolumn{8}{|c|}{ Particular goals $\left(\mathbf{f}_{\mathrm{K}}\right)$} \\
\hline & $\begin{array}{c}\text { AEE } \\
\left(P_{1}\right)\end{array}$ & $\begin{array}{l}\mathrm{DC} \\
\left(\mathbf{P}_{2}\right)\end{array}$ & $\begin{array}{l}\text { NPV } \\
\left(\mathbf{P}_{3}\right)\end{array}$ & $\begin{array}{l}\mathbf{P m} \\
\left(\mathbf{P}_{4}\right)\end{array}$ & $\begin{array}{l}\text { PED } \\
\left(P_{5}\right)\end{array}$ & $\begin{array}{l}\text { API } \\
\left(\mathbf{P}_{6}\right)\end{array}$ & $\ldots$ & $\begin{array}{c}\cdots \\
\left(\mathbf{P}_{\mathrm{m}}\right)\end{array}$ \\
\hline $\mathrm{O} 1$ & $\mathrm{c}_{11}$ & $\mathrm{c}_{12}$ & $\mathrm{c}_{13}$ & $\mathrm{c}_{14}$ & $\mathrm{c}_{15}$ & $\mathrm{c}_{16}$ & $\ldots$ & $\mathrm{c}_{1 \mathrm{~m}}$ \\
\hline $\mathrm{O} 2$ & $\mathrm{c}_{21}$ & $\mathrm{c}_{22}$ & $\mathrm{c}_{23}$ & $\mathrm{c}_{24}$ & $\mathrm{c}_{25}$ & $\mathrm{c}_{26}$ & $\ldots$ & $\mathrm{c}_{2 \mathrm{~m}}$ \\
\hline $\mathrm{O} 3$ & $\mathrm{c}_{31}$ & $c_{32}$ & $\mathrm{c}_{33}$ & $\mathrm{c}_{34}$ & $\mathrm{c}_{35}$ & $\mathrm{c}_{36}$ & $\ldots$ & $\mathrm{c}_{3 \mathrm{~m}}$ \\
\hline$\ldots$ & $\ldots$ & $\ldots$ & $\ldots$ & $\ldots$ & $\ldots$ & $\ldots$ & $\ldots$ & \\
\hline$\overline{\mathrm{O}_{\mathrm{n}}}$ & $\mathrm{C}_{\mathrm{B} 1}$ & $\mathrm{C}_{\mathrm{B} 2}$ & $\mathrm{C}_{\mathrm{B} 3}$ & $\mathrm{C}_{\mathrm{B} 4}$ & $\mathrm{C}_{\mathrm{B} 5}$ & $\mathrm{C}_{\mathrm{B} 6}$ & $\ldots$ & $\mathrm{Cnm}$ \\
\hline
\end{tabular}

\section{Results}

Based on the data presented in the final "payment matrix" of the "game with nature", we can:

- produce a qualitative factor analysis of the consequences of decisions made, i.e. determine the degree of environmental friendliness and efficiency of decisions;

- to determine the full range of variation of the "costs" of the options of measures according to the values of their absolute minimum and maximum;

- solve the matrix, i.e. to substantiate the choice of the option of environmental and economic decisions on the possibilities and conditions for the implementation of the planned economic activity. 
To solve the final "payment matrix" of the "game with nature", let us use the well-proven minimax selection criteria. The data thus obtained for solving the final "payment matrix" is presented in Table 3.

The estimated function $\gamma$, assumed by Hurwitz and chosen as the criterion for choosing the best solution, expresses a compromise way of making a decision, which lies between the point of view of extreme optimism and extreme pessimism:

$$
\gamma=\mu k_{1}+(1-\mu) k_{2}
$$

where $\mu$ - indicator of pessimism-optimism within $0<\mu<1$.

When $\mu=1$, the Hurwitz criterion turns into a maxmin criterion. When $\mu=0$ - in the criterion of "gambler".

Table 3. The decision of the final "payment matrix" of "game with nature".

\begin{tabular}{|c|c|c|c|c|c|c|c|c|c|c|c|}
\hline \multirow{3}{*}{$\begin{array}{c}\text { Option of } \\
\text { environmental } \\
\text { and economic } \\
\text { decisions }\end{array}$} & \multicolumn{7}{|c|}{ "Condition of nature" } & \multicolumn{2}{|c|}{$\begin{array}{l}\text { Possible } \\
\text { positions on } \\
\text { the option: }\end{array}$} & \multicolumn{2}{|c|}{$\begin{array}{c}\text { Minimax } \\
\text { criteria }\end{array}$} \\
\hline & \multicolumn{7}{|c|}{ Particular goals $\left(\mathrm{f}_{\mathrm{K}}\right)$} & $\min$ & Max & & \\
\hline & $\begin{array}{l}\text { AEE } \\
\left(\mathrm{P}_{1}\right)\end{array}$ & $\begin{array}{l}\mathrm{DC} \\
\left(\mathrm{P}_{2}\right)\end{array}$ & $\begin{array}{l}\mathrm{NPV} \\
\left(\mathrm{P}_{3}\right)\end{array}$ & $\begin{array}{l}\mathrm{Pm} \\
\left(\mathrm{P}_{4}\right)\end{array}$ & $\begin{array}{l}\text { PED } \\
\left(\mathrm{P}_{5}\right)\end{array}$ & $\begin{array}{l}\text { API } \\
\left(\mathrm{P}_{6}\right)\end{array}$ & $\begin{array}{l}\cdots \\
(\mathrm{Pm})\end{array}$ & $\begin{array}{l}\text { of } \\
\text { line } \\
\left(\alpha_{n}\right) \\
\text { min }\end{array}$ & $\begin{array}{c}\left(\beta_{\mathrm{n}}\right) \\
\max \end{array}$ & $\begin{array}{l}\text { 音 } \\
\text { 离 } \\
\text { 究 }\end{array}$ & 兽 \\
\hline $\mathrm{O} 1$ & $\mathrm{c}_{11}$ & $\mathrm{c}_{12}$ & $\mathrm{c}_{13}$ & $\mathrm{c}_{14}$ & $\mathrm{c}_{15}$ & $\mathrm{c}_{16}$ & & $\alpha_{1}$ & $\beta 1$ & & \\
\hline $\mathrm{O} 2$ & $c_{21}$ & $c_{22}$ & $c_{23}$ & $\mathrm{c}_{24}$ & $\mathrm{c}_{25}$ & $\mathrm{c}_{26}$ & & $\alpha_{2}$ & B2 & & \\
\hline $\mathrm{O} 3$ & $c_{31}$ & $\mathrm{c}_{32}$ & $\mathrm{c}_{33}$ & $\mathrm{c}_{34}$ & $\mathrm{c}_{35}$ & $\mathrm{c}_{36}$ & & $\alpha_{3}$ & B3 & K1 & K2 \\
\hline$\ldots$ & $\ldots$ & $\cdots$ & $\ldots$ & $\ldots$ & $\ldots$ & $\ldots$ & & $\ldots$ & $\ldots$ & & \\
\hline $\mathrm{O}_{\mathrm{n}}$ & $\mathrm{Cn}_{1}$ & $\mathrm{C}_{\mathrm{n} 2}$ & $\mathrm{C}_{\mathrm{n} 3}$ & $\mathrm{C}_{\mathrm{n} 4}$ & $\mathrm{C}_{\mathrm{n} 5}$ & $\mathrm{C}_{\mathrm{n} 6}$ & & $\alpha_{\mathrm{n}}$ & $\beta \mathrm{n}$ & & \\
\hline
\end{tabular}

The rule of choice, according to the Hurwitz criterion, is formed as follows: according to the "payment matrix", the estimated function $\gamma_{n}$ is determined for each considered variant. The best is the option (options), the value of $\gamma_{n}$, which is as close as possible to the value of $\gamma$ :

$$
\gamma_{n} \rightarrow \gamma
$$

\section{Discussion}

An analysis of domestic and foreign experience of the basics of an EIA demonstrates a transition to a "preventive-environmental" approach, which allows assessing economic costs and profits, the degree of environmental safety, social and other related consequences of the planned activity in the specific conditions of its location.

The decision to finance an investment project must be preceded by an assessment of the completeness and objectivity of taking into account all environmental and economic factors, combining environmental impact assessment and investment design. This is necessary to determine the possible environmental, social and economic impacts of the project.

The proposed methodology for environmental impact assessment and justification of environmental investments of industrial enterprises is a step-by-step algorithm aimed at implementing a unified assessment and selection of the best options for environmental and economic decisions on the possibility and conditions for the implementation of the planned economic activity. 


\section{Conclusions}

Conducting a comprehensive economic assessment of environmental impact is impossible when using one or two methods, even the most universal. The chain of relations "societyenvironment-economy" is so multifaceted that a comprehensive approach is needed, taking into account the specific conditions and goals in each economic situation. For this purpose, the presented article has improved the ecological-economic toolkit for making managerial decisions on the possibility and conditions for the implementation of the planned economic activity, under which:

- a classification of causes of environmental pollution has been developed, presented in the form of a tree of systems (TS), which allows a clear decomposition of the causes of environmental pollution,

- a tree of goals (TG) of the project of the planned economic activity was built, ensuring an increase in the validity of making ecological and economic decisions about the possibility and conditions for its implementation;

- a strategy was developed (a decision tree (TD)) and a mathematical description of the procedure for making ecological and economic decisions, using the "game with nature" methodology and allowing for real-time making an objectively reasonable choice of options for implementing economic activity, taking into account all the known information.

To improve the situation in our country it is necessary:

First, the improvement of the legal framework governing environmental impact assessment, through the introduction of mandatory long-term planning of economic and environmental development of the areas under development, including long-term economic assessment of environmental impact.

Secondly, approbation of western methodologies and environmental impact assessment systems, taking into account the possibility of estimating the reproduction costs for the reproduction of resources and ecosystems. Only by adapting such a multifunctional system will we be able to ensure the long-term and sustainable development of the economy.

\section{References}

1. A. Moura, Review of Economic Dynamics 1, 48-63 (2018)

2. B. Ozorhon, A. Batmaz, S. Caglayan, Renewable and Sustainable Energy Reviews 1, 217-226 (2018)

3. D. Blandford, J.B. Braden, J.S. Shortle, Encyclopedia of Agriculture and Food Systems 1, 18-34 (2014)

4. Ch. Gidlow, E. van Kempen, Urban Forestry \& Urban Greening 1, 322-333 (2018)

5. Generating a framework to facilitate decision making in renewable energy investments, Renewable and Sustainable Energy Reviews 1, 217-226 (2018)

6. J. Du, W. Li, B. Lin, Y. Wang, China Journal of Accounting Research 1, 213-232 (2018)

7. J. Luo, China Journal of Accounting Research 1, 359-378 (2017)

8. N. Gal, I. Milstein, A. Tishler, C.K. Woo, Energy Economics 1, 233-240 (2017)

9. Ph. Brown, A.J. Daigneault, E. Tjernström, W. Zou, Quantitative game theory applied to economic problems, Handbook of Statistics (Elsevier, 2018)

10. Ph. Brown, A.J. Daigneault, E. Tjernström, W. Zou, Natural disasters, social protection, and risk perceptions 1, 322-333 (2018)

11. S. Cano-Berlanga, J.-M. Giménez-Gómez, C. Vilella, Y. Zhang, J. Shen, Y. Li, Journal of Environmental Management 1, 341-354 (2018) 